\title{
O(S) PROCESSO(S) DE ORIENTAÇÃO: REFLEXÕES A PARTIR DE CASOS HISTÓRICOS E HIPOTÉTICOS
}

\author{
EL (LOS) PROCESO (S) DE ORIENTACIÓN: REFLEXIONES DE CASOS \\ HISTÓRICOS E HIPOTÉTICOS
}

\author{
THE ADVISING PROCESS (ES): REFLECTIONS FROM HISTORICAL AND \\ HYPOTHETICAL CASES
}

\author{
Pedro Maciel de Paula GARCIA ${ }^{1}$ \\ Carolina Santos BONFIM ${ }^{2}$ \\ Delarim Martins GOMES ${ }^{3}$
}

RESUMO: Pesquisas no campo da formação de professores têm contemplado de forma incipiente as relações entre orientandos e orientadores, principalmente no que concerne ao planejamento didático da orientação. Da mesma forma, a legislação brasileira não especifica qual(is) o(s) papel(is) do orientador nos diferentes níveis de ensino. Neste ensaio, refletimos sobre o(s) processo(s) de orientação por meio de casos históricos e hipotéticos, inspirados em situações reais, de modo a fomentar a ampliação de discussões sobre esta temática. A partir dos casos, evidenciamos elementos e posturas inerentes à orientação, como herança de capital intelectual, influência na visão de mundo e divergências de posturas ideológicas. $O$ processo de orientação é mais influenciado pelas vivências dos orientadores do que por aspectos de caráter educacional.

PALAVRAS-CHAVE: Orientação. Formação docente. Ensino Superior.

RESUMEN: La investigación en el campo de la formación del profesorado ha contemplado incipientemente las relaciones entre estudiantes y orientadores, especialmente en lo que respecta a la planificación didáctica de la orientación. Asimismo, la ley brasileña no especifica cuál es la función del orientador en los diferentes niveles de educación. En este ensayo reflexionamos sobre el (los) proceso (s) de orientación a través de casos históricos e hipotéticos, inspirados en situaciones reales, con el fin de propiciar la expansión de las discusiones sobre este tema. A partir de los casos, destacamos elementos y actitudes inherentes a la orientación, como la herencia del capital intelectual, la influencia en la cosmovisión y las divergencias en las actitudes ideológicas. El proceso de orientación está más influenciado por las experiencias de los mentores que por los aspectos educativos.

PALABRAS CLAVE: Orientación. Formación del profesorado. Enseñanza Superior.

${ }^{1}$ Universidade Federal de Mato Grosso (UFMT), Cuiabá - MT - Brasil. Professor Adjunto da Faculdade de Geociências. Doutorado em Geologia (UFBA). ORCID: https://orcid.org/0000-0002-7986-7218. E-mail: pedrompgarcia@yahoo.com.br

${ }^{2}$ Universidade de Brasília (UNB), Brasília - DF - Brasil. Doutoranda no Programa de Pós-Graduação em Educação em Ciências. ORCID: https://orcid.org/0000-0001-8271-4098. E-mail: carol.sb88@gmail.com

${ }^{3}$ Universidade Federal de Mato Grosso (UFMT), Cuiabá - MT - Brasil. Professor Associado do Instituto de Educação. Doutorado em Educação (UNESP). ORCID: https://orcid.org/0000-0001-8703-6038. E-mail: profdelarim@gmail.com

RIAEE - Revista Ibero-Americana de Estudos em Educação, Araraquara, v. 16, n. esp. 1, p. 850-865, mar. 2021. e-ISSN: 1982-5587 
ABSTRACT: The teacher education research has incipiently contemplated the relationship between students and advisors, especially regarding advising didactic planning. Likewise, Brazilian law does not specify the advisor's role (s) in different levels of education. In this essay, we reflect on the orientation process (es) through historical and real situationsinspired hypothetical cases to encourage discussions about this theme. Based on these cases, we highlight advising elements and attitudes, such as inheritance of intellectual capital, influence on the worldview, and ideological divergences. The mentors' experiences influence the advising process (es) more than the educational aspects.

KEYWORDS: Advising. Teacher education. Higher Education.

\section{Introdução}

Pesquisas sobre orientação no Brasil são incipientes (CORRÊA, 2012) e são, em sua maioria, voltadas para a atuação dos professores orientadores de estágio curricular docente (WINCH; TERRAZZAN, 2011). Em contrapartida, a temática é mais explorada em âmbito internacional, abordando principalmente relacionamentos entre orientadores e orientandos e como eles influenciam na formação de professores e pesquisadores (KNOX et al., 2006; PUNYANUNT-CARTER; WRENCH, 2008; BLOOM et al., 2007), existindo, assim, lacunas a respeito do entendimento da relação orientador-orientando no cenário brasileiro.

A legislação brasileira contempla a figura do orientador no Ensino Superior em estágios docentes de cursos de licenciatura (BRASIL, 1996; BRASIL 2002a) e da PósGraduação (BRASIL, 2010), ainda em monografias e atividades de formação profissional em diretrizes curriculares de cursos de graduação (FRAUCHES, 2008). Entretanto, a legislação e as políticas públicas não explicitam quais funções devem ser empenhadas por orientadores, tampouco preveem formação específica para exercer tal obrigação.

Neste ensaio, tratamos sobre posturas e atitudes de professores e estudantes perante o processo de orientação por meio de casos históricos e hipotéticos (inspirados em situações reais). Utilizamos estes cenários como pano de fundo para debater como o ato de orientar pode ser exercido com intencionalidade, lançando mão de conhecimentos pedagógicos (dentre outros), e contribuir para a formação de professores e pesquisadores.

\section{O que se discute sobre a orientação?}

As pesquisas voltadas para a formação de professores focadas no nível superior, através da atuação dos "professores formadores", têm timidamente despontado no século XXI, já que a educação básica constitui o foco principal das pesquisas pedagógicas (WINCH; 
TERRAZZAN, 2011). Desta forma, tem se dado evidência, no Brasil, às pesquisas sobre orientação de estágio docente, visto que é um momento essencial da formação de futuros professores, investigando, por exemplo, as relações entre graduandos de licenciaturas e seus orientadores de estágio docente. Contudo, ao processo de orientação na pesquisa e na pósgraduação não tem se dado a devida importância, fato corroborado pela incipiência de pesquisas brasileiras com essa temática (CORRÊA, 2012), em comparação com a literatura internacional (KNOX et al., 2006; PUNYANUNT-CARTER; WRENCH, 2008; BLOOM et al., 2007; CURTIN; STEWART; OSTROVE, 2013; BARRES, 2013; WOOLSTON, 2015).

Como citado anteriormente, o papel do orientador no estágio docente vem sendo discutido por diversos autores no Brasil, destacamos as pesquisas de Daniel (2009), Winch e Terrazzan (2011), Assis e Rosado (2012), Quadros, Duarte e Botelho (2015) e Feldkercher (2016). Como exemplo, Winch e Terrazzan (2011) evidenciam vivências prévias, recepção por um colega orientador mais experiente, ou mesmo a motivação própria para buscar leituras e conversas com outros profissionais, como meios de capacitação para o processo de orientação em disciplinas de estágio curricular. Já Feldkercher (2016) reconhece a relevância do papel do orientador e sua influência na formação de futuros professores, apontando que o relacionamento entre orientadores e estagiários deva ser galgado em um caráter pedagógico, considerando compartilhamento de conhecimentos, conselhos, aprimoramento de práticas pedagógicas e soluções para problemas, em um ambiente permeado pelo diálogo. Neste âmbito, Daniel (2009) aponta a importância de aproximar os orientadores (professores universitários) dos professores regentes/supervisores (da educação básica), de modo a diminuir as distâncias causadas por contrastes de privilégios, poder e status.

Muitas estratégias mencionadas pelos supracitados autores encontram correspondência com as pesquisas centradas no entendimento da orientação em pesquisa e pós-graduação. Entretanto, devemos salientar que, apesar das similitudes, esse processo apresenta características particulares nos diferentes níveis de ensino. No que se refere à orientação, Dias, Patrus e Magalhães (2011) apontam dificuldades na conclusão de trabalhos finais, muitas vezes causadas pelo despreparo dos professores orientadores. Neste sentido, os autores propõem uma estratégia para o desenvolvimento de monografias, dissertações e teses, com direcionamentos para orientadores e, principalmente, orientandos, buscando contribuir para mitigar a carência de aspectos didáticos na orientação de trabalhos de conclusão. São oferecidos um modelo para o desenvolvimento de tais trabalhos e dicas para minimizar percalços que dificultam o processo de orientação.

RIAEE - Revista Ibero-Americana de Estudos em Educação, Araraquara, v. 16, n. esp. 1, p. 850-865, mar. 2021. e-ISSN: 1982-5587 
Ao estudar a relação entre orientadores e orientandos em pós-graduações stricto sensu, Viana (2008, p. 99) pondera que cada orientador "tem o seu próprio estilo de trabalho, construído a partir da sua própria experiência, pessoal e profissional, dos seus valores, da sua crença no papel de educador, enfim, da sua própria visão de mundo". A autora considera que os aspectos afetivos, profissionais, teóricos-metodológicos e institucionais influenciam as atividades exercidas pelos orientadores. Fazendo uma comparação com autores internacionais, percebemos que estes lançam mão de características excessivamente subjetivas (que não são inatas), atribuindo adjetivos que remetem a um juízo de valor de orientadores e da orientação, em geral, como identificamos em Bloom et al. (2007), Curtin, Stewart e Ostrove (2013) e Barres (2013).

Bloom et al. (2007) sinalizam que a literatura sobre orientação confirma que o fator mais importante para o "sucesso" de um estudante de pós-graduação é a relação com seu orientador. Os autores sumarizam características que os orientandos procuram no que consideram como "bons orientadores": demonstrar se importar com os estudantes, serem acessíveis, serem modelos para questões pessoais e profissionais, trazerem conselhos de orientação individualizados, serem proativos para integrar os estudantes na profissão, serem bons ouvintes, incentivar os estudantes, saber "podar" na hora certa mas deixar a decisão para os orientandos.

Ao comparar estudantes da pós-graduação estadunidenses, Curtin, Stewart e Ostrove (2013) concluíram que o suporte dos orientadores está associado ao sentimento de pertencimento à comunidade e autoconfiança dos orientandos, ou seja, quanto mais apoiado pelo orientador, melhor o orientando se sente com relação à pesquisa e ao seu desempenho. As habilidades científicas e de mentoria são sinalizadas por Barres (2013), sem especificá-las, como as características mais importantes para a escolha de orientador da pós-graduação, sendo primordiais no treinamento de pós-graduandos para serem "bons cientistas". O autor assevera que uma "boa mentoria" é uma grande responsabilidade e vai além da pósgraduação, indicando que o orientador deve se preocupar com os passos seguintes do orientando. Barres (2013), ainda, expressa preocupação de que o aumento da competição por fundos de pesquisa tende a pôr em risco a "boa prática" de orientação.

Em síntese, as pesquisas refletem a escassez de trabalhos que se atêm à atividade de orientação como prática docente. Ainda assim, estão principalmente relacionadas à orientação de estágio docente, da descrição da personalidade do orientador "ideal" e menos comumente de pesquisas, monografias, dissertações e teses, reflexões que aqui propomos. 


\title{
O que diz a legislação brasileira sobre orientação?
}

A única menção direta ao processo de orientação na Lei de Diretrizes e Bases da Educação Nacional - LDB (BRASIL, 1996), que define a organização educacional brasileira, é dada no Título IV (Dos Profissionais da Educação), especificamente no artigo 64:

\begin{abstract}
A formação de profissionais de educação para administração, planejamento, inspeção, supervisão e orientação educacional para a educação básica será feita em cursos de graduação em pedagogia ou em nível de pós-graduação, a critério da instituição de ensino, garantida, nesta formação, a base comum nacional (BRASIL, 1996, p. 26-27, grifo nosso).
\end{abstract}

No artigo seguinte, a LDB se refere à carga horária mínima exigida para a formação de professores: "a formação docente, exceto para a educação superior, incluirá prática de ensino de, no mínimo, trezentas horas" (BRASIL, 1996, p. 27). A referida prática docente é materializada pelos estágios curriculares em docência, que são regulamentados pelas resoluções 1 e 2 do Conselho Nacional de Educação/Conselho Pleno (CNE/CP), de fevereiro de 2002 (BRASIL, 2002a; 2002b) que instituem, respectivamente, diretrizes para a formação de professores da educação básica e duração e carga horária dos cursos de licenciatura em nível superior. A primeira resolução menciona práticas de "orientação inerentes à atividade docente" (BRASIL, 2002a, p. 1), incluindo atividades desenvolvidas no âmbito do ensino, da pesquisa e da extensão, enquanto a segunda fixa 400 horas de estágio curricular (BRASIL, $2002 b)$, sem mencionar a figura do professor orientador.

No caso dos estudantes de Pós-Graduação, a Portaria n 76, de 14 de abril de 2010, da Coordenação de Aperfeiçoamento de Pessoal de Nível Superior (CAPES), indica o estágio de docência como "parte integrante da formação do pós-graduando, objetivando a preparação para a docência, e qualificação do ensino de graduação" (BRASIL, 2010, p. 8). O mesmo documento torna obrigatório o estágio de docência para bolsistas do Programa de Demanda Social e determina que a supervisão, avaliação e acompanhamento deste ficará a cargo da comissão de bolsas do programa de pós-graduação em questão.

O desenvolvimento do ensino e da pesquisa, além da promoção das atividades de extensão, são abordados no Capítulo IV da LDB, que versa sobre a Educação Superior. Nas recomendações gerais para as diretrizes curriculares dos cursos de graduação do Brasil, é apontado que:

As Diretrizes Curriculares devem contemplar orientações para as atividades de estágio, monografia e demais atividades que integrem o saber acadêmico à prática profissional, incentivando o reconhecimento de 
habilidades e competências adquiridas fora do ambiente escolar. Desta forma, estaria assegurada uma formação de acordo com as especificidades de cada curso, preservando, contudo, o princípio de flexibilização e adaptação às demandas da sociedade (FRAUCHES, 2008, p. 47, grifo nosso).

Desta forma, notamos que, embora não seja uma exigência da LDB para todos os cursos de Ensino Superior do Brasil, as diretrizes curriculares remetem diretamente à atividade da orientação como obrigatória em diversas etapas da formação acadêmica, sem, no entanto, garantir uma formação sobre como orientar.

Ao tratar de políticas públicas na universidade, Cunha (2003) afirma que o professores, frequentemente, se veem obrigados a extrapolar suas cargas horárias acadêmicas, dando importância a finais de semana e feriados para se dedicarem às suas produções intelectuais. A autora aponta que, neste contexto, o individualismo é exacerbado, com grande valor dado ao que os docentes produzem individualmente ou com seus orientandos que, em muitos casos, dispõem de produções intelectuais próprias para serem somadas à autoria do orientador. Da mesma forma que chamamos atenção para a ausência de diretrizes sobre a atividade de orientação nos documentos oficiais do Brasil, também salientamos a necessidade de desenvolvimento de políticas públicas que direcionem, de forma explícita, o papel do orientador, implicando em uma tomada de consciência com relação a essa atividade, que vem sendo realizada de forma individualista, sem intencionalidade e sem a devida atenção.

\section{Entendendo a relação orientador-orientando: casos históricos}

Assim como todo trabalho desenvolvido em ambiente acadêmico, consideramos que o processo de orientação é fulcral para a formação de profissionais técnicos, acadêmicos e da área da Educação. Sendo um trabalho realizado em uma equipe restrita (não mais do que três membros, se houver uma dupla de orientandos ou de orientadores), a construção de uma relação de cooperação sinérgica é um dos atributos para que o desenvolvimento do discente seja potencializado em seu máximo. Neste sentido, trabalhamos breves relatos históricos e de experiências hipotéticas, livremente baseadas em episódios reais, para discutir tais relações.

A relação de orientação intelectual entre discípulos e mentores é tão antiga quanto a própria documentação do conhecimento humano, bem ilustrada pelo registro do pensamento socrático por seus pupilos, sendo Platão o mais aludido deles. A própria sobrevivência das ideias de Sócrates foi garantida pela devoção de seus aprendizes (Platão, Aristófanes e Xenofonte), já que não existem evidências de que ele mesmo tenha publicado algo em vida. Platão, além de influenciado pelas considerações morais e éticas de seu mestre, buscou o 
caminho da filosofia como forma de manter o legado socrático, sendo um desvio em seus planos iniciais de se dedicar à vida política, conforme assinala Trabattoni (2012). Neste caso, Sócrates, enquanto mestre, moldou não somente os pensamentos filosóficos, mas também a visão de mundo de Platão, corroborando com Bloom et al. (2007), ao admitir que orientadores servem de modelo para seus mentorados.

A ascendência do pensamento de um professor sobre um discípulo é, da mesma forma, bem ilustrada pela relação de Anísio Teixeira (1900-1971) com John Dewey (1859-1952). O educador brasileiro conheceu Dewey em seu mestrado e foi responsável por traduzir suas ideias para o português e implantá-las no sistema educacional brasileiro, por meio de políticas públicas que perduram desde década de 1930 até a atualidade (SOUZA; MARTINELI, 2009). Influenciado pelas ideias deweyanas e por suas próprias experiências, Anísio Teixeira entendia a orientação dos discentes como pilar central no processo educacional (CARBELLO; RIBEIRO, 2015).

Ainda no âmbito da perpetuação e difusão de ideias de professores por parte de seus alunos, destacamos a relação do filósofo Karl Popper (1902-1994) com os discentes Paul Feyeraband (1924-1994) e Imri Lakatos (1922-1974), que, apesar de não serem formalmente orientados por Popper, tiveram suas ideias fortemente influenciadas por ele. Da mesma forma, George Soros (1930-), outro discípulo/aluno de Popper, se sobressai ao se empenhar em divulgar suas concepções sobre "sociedades abertas" em diversos países e se basear nas teorias do seu mentor sobre conjecturas e refutações para orientar seus investimentos e intervenções sociais (UMPLEBY, 2007).

Os casos supramencionados, nos quais mestres e discípulos ou, especificamente, orientadores e orientandos são alçados a posições de amplo reconhecimento, não são isolados, provavelmente demonstrando uma propensão ao desenvolvimento de pesquisas com grande potencial de alcance na comunidade científica. Será que o alcance é dado pelos temas ou por quem orienta as pesquisas? Não são raros os episódios de pesquisadores receptores de prêmios Nobel que foram orientandos por cientistas laureados pela mesma premiação. Há também casos como o de Arnold Sommerfeld (1868-1951), um dos físicos que ensinou e orientou mais receptores do prêmio Nobel, e que nunca foi laureado, embora tenha sido indicado 84 vezes (CHEREP, 2020).

A trajetória de Marie Curie (1867-1934), igualmente, ilustra o peso que ser orientado por um pesquisador notável exerce na carreira acadêmica de um(a) jovem cientista. Ela foi a primeira pessoa e a única mulher a ser duas vezes laureada com prêmios Nobel (1903 em Física e 1911 em Química). O seu primeiro prêmio foi dividido entre seu cônjuge, Pierre 
Curie (1859-1906), ela e seu orientador de doutorado Henri Becquerel (1852-1908), em reconhecimento às pesquisas em conjunto que realizaram sobre o "fenômeno da radiação descoberto pelo Professor Henri Becquerel” (SKWARZEC, 2011, p. 1550, tradução nossa). Embora o prêmio fosse endereçado aos três, com Pierre citado como primeiro autor, ele foi concedido graças aos resultados obtidos pelas pesquisas de Marie, sob supervisão de Becquerel, um cientista já reconhecido pelas investigações pioneiras do fenômeno da radiação.

No caso de Marie Curie, esta relação ainda é permeada pelo sexismo e xenofobia, impregnados no meio científico. Suas publicações só tiveram repercussão na academia quando ela saiu da posição de primeira autora e sucedeu autores homens como Pierre Curie e Gustave Bémont, além de suprimir seu sobrenome polonês (WIRTÉN, 2015). Embora o percurso de Marie seja frequentemente romantizado, a colocando como "apoiada em ombros de gigantes", o mérito da pesquisadora é ainda maior quando consideramos que ela discordou de seu orientador, Becquerel, que havia abandonado a pesquisa com "raios de urânio" (PETELENZ, 2013) - uma combinação entre partículas alfa e raios gama. A sua teimosia, considerando os "raios de urânio" como problema fundamental de sua pesquisa, resultou em suas principais contribuições às ciências, que lhes rendeu o prêmio Nobel no mesmo ano de apresentação da tese de Marie Curie. Neste caso, a discordância não rendeu um afastamento entre os dois, tampouco uma paralisação das pesquisas.

As ciências sociais brasileiras nos fornecem outro caso representativo de cisão entre orientador e orientando, neste caso muito mais profunda, visto que resultou em trajetórias acadêmicas e políticas divergentes, ainda que a amizade tenha sido preservada entre as partes: Florestan Fernandes (1920-1995) e Fernando Henrique Cardoso (1931-). A aproximação entre os dois começou em 1951, e no ano seguinte, ao assumir a vaga de professor assistente na Universidade de São Paulo, Florestan nomeou Fernando Henrique como seu assistente, causando "ciúme" entre os outros membros de seu grupo de pesquisa, de acordo com Bordignon (2013). O autor narra que juntos os dois mobilizam recursos sociais de toda a universidade, porém divergências de ideias resultaram em um afastamento, levando Cardoso a ameaçar mudar de orientador de doutorado, no período anterior à apresentação de sua tese.

A ruptura entre os dois foi considerada definitiva em 1968, quando Florestan Fernandes demandou um posicionamento público e institucional contra a ditadura militar e Fernando Henrique, ao contrário, defendeu um posicionamento burocrático, em ata, sob a forma de nota de repúdio (BORDIGNON, 2013). As posições divergentes se deram no campo teórico, já que o orientador seguiu com posições mais alinhadas com o socialismo e o 
marxismo e o orientando aderiu paulatinamente a posições mais liberais, e também políticas, visto que Florestan Fernandes foi um dos fundadores e deputado federal pelo Partido dos Trabalhadores (PT) e Fernando Henrique Cardoso um dos principais expoentes do Partido da Social Democracia Brasileiro (PSDB), pelo qual foi eleito presidente duas vezes. Os dois partidos, em campos francamente distintos do espectro político, foram os principais antagonistas da política brasileira nas décadas de 1990 e 2000.

Vemos, até então, que os episódios de caráter histórico aqui relatados apresentam limitações no que se refere ao processo de orientação, devido à pouca relevância dada pelos historiadores aos entendimentos sobre o que é orientar em variados âmbitos (psicológico, emocional, social, pedagógico, entre outros). Ainda, são geralmente centrados em relações harmônicas e exitosas entre orientadores e orientandos, mentores e pupilos, oferecendo relatos empobrecidos ou pouco problematizados. Os relacionamentos que envolvem os processos de mentoria e orientação nem sempre se dão em perfeita consonância. Para exemplificar alguns dos cenários possíveis deste contexto, trazemos a seguir quatro narrativas inspiradas em situações reais.

\section{Entendendo a relação orientador-orientando: casos inspirados em situações reais}

O primeiro caso se refere ao estudante Kauê e seu orientador, o pesquisador Ubirajara. Em todo o processo de orientação, Kauê buscava conhecimentos cada vez mais distantes do seu foco de pesquisa. Vendo o potencial do estudante e a sua crescente curiosidade, Ubirajara procurou dar um caráter diversificado para a pesquisa desenvolvida por Kauê, de modo a suprir sua curiosidade.

Apesar de ser necessário "podar" o orientando (BLOOM et al., 2007), algo que Ubirajara procurou fazer com as buscas incessantes de Kauê, o orientador propôs então: utilizar diferentes métodos, sem fugir do objetivo da pesquisa, fazendo com que o estudante canalizasse a sua curiosidade. A sabedoria de Ubirajara foi essencial para o crescimento de Kauê, evitando a sua frustração com a pesquisa, que poderia ter sido ocasionada caso o estudante sentisse que seus conhecimentos estavam sendo restringidos. Desse modo, consideramos que podar não necessariamente implica em limitar o olhar do orientando, mas canalizar uma curiosidade dispersa expandindo seu foco de interesse.

A adoção de uma postura contrastante do orientador Antônio foi primordial para a frustração da estudante Iracema, que era dotada de uma curiosidade incessante, como o estudante do caso anterior. Frequente alvo de questionamentos, Antônio optou pela estratégia 
de não cobrar cronogramas e de cercear a pesquisa bibliográfica de Iracema, que passou a sentir que seus conhecimentos estavam estagnando e sua pesquisa de campo não seria capaz de evoluir com restritas fontes de conhecimento. Então, embates intelectuais acabaram por ser inevitáveis, já que não foi encontrado um ponto comum entre a necessidade do aluno e do professor. Para Iracema, então, a imagem de Antônio como uma possibilidade de segurança foi desfeita e substituída por receio, pela possibilidade de conflitos, o que a levou a buscar outro orientador, pois Iracema havia idealizado seu projeto.

Um terceiro caso é o da orientadora Margareth e do orientando Guaraci. Visando motivar uma produção prolífica de seu orientando, Margareth cobrava em demasia resultados e prazos específicos, trazendo sempre um feedback de críticas pouco construtivas. Percebendo que o seu empenho e os seus resultados não eram devidamente avaliados ou reconhecidos, o orientando Guaraci se desmotivou e passou a buscar apoio em outras figuras, como outros pesquisadores e colegas estudantes, tornando a figura de sua orientadora meramente virtual.

Guaraci não pôde trocar de orientador, visto que seu projeto foi viabilizado por Margareth. É comum que pesquisadores em formação adiram a projetos maiores já em andamento, idealizados pelos orientadores, isto faz parte da relação hierárquica estabelecida entre orientando e orientador. $\mathrm{O}$ orientador raramente tende a aceitar um projeto no qual não tenha experiência no assunto, formação ou que tenha que buscar novas fontes de financiamento para desenvolver.

Woolston (2015) relata que, embora não seja abordado com frequência, a relação entre orientador e orientando é, por vezes, problemática e pode resultar em pontos de inflexão na carreira de estudantes. Não raramente, orientadores, para reafirmar a posição de poder, requisitam análises ou correções extras que, provavelmente, pouco contribuirão para melhorar a qualidade do trabalho final. Nestes casos, os estudantes devem procurar melhorar a comunicação e buscar conselhos com colegas ou professores que possam opinar de forma imparcial.

O quarto e último caso, o da orientadora Inã e da orientanda Lina, que raramente aparecia nos encontros marcados para discutir sua pesquisa. Lina, além de não responder às comunicações da orientadora, não atendia o cronograma e não desenvolvia as atividades de sua pesquisa, tornando a relação entre as duas cada vez mais insustentável. Embora Inã se mostrasse sempre disponível, a orientanda não buscava a orientação nem justificava suas ausências. Ao buscar Lina para prosseguir com seu projeto de mestrado, Inã foi verbalmente destratada, o que a levou a desistir da orientação. 
Punyanunt-Carter e Wrench (2008) concluíram que credibilidade, comportamento frente a conflitos, estilo de mentoria e agressão verbal influenciam a relação orientadororientando. Segundo os autores, a credibilidade dos orientadores, para os orientandos, é relacionada ao uso de estratégias para resolução de conflitos baseadas em soluções, assim como a confiabilidade é inversamente proporcional às atitudes de confronto. Os resultados da pesquisa ainda mostraram que a agressão verbal é considerada um obstáculo na credibilidade dos orientadores.

A relação entre orientador e orientando é, por vezes, comparada a um contrato ou um casamento, uma vez que contratos são galgados em direitos e deveres estabelecidos previamente e casamentos podem ser abusivos ou confiáveis. Além disso, todas essas relações podem ser desfeitas quando o respeito não for mútuo. Embora alguns desses paralelos possam ser válidos, vemos essas comparações como problemáticas, pois não descrevem a complexidade da relação orientando-orientador, que apresenta características únicas, desconsiderando completamente o caráter pedagógico do processo.

Segundo Knox et al. (2006), os professores identificam demanda de tempo e satisfação pessoal como custos e benefícios da orientação, respectivamente. Para os orientadores, "boas" relações com os orientandos são galgadas em características pessoais e profissionais positivas, respeito mútuo, comunicação aberta, trajetórias profissionais similares entre orientadores e orientandos e falta de conflito. Em contraste, relações são consideradas problemáticas quando apresentam perspectivas negativas de características pessoais, falta de respeito, problemas no desenvolvimento da pesquisa, problemas de comunicação, discórdias no relacionamento, evasão de conflito e sentimento de trabalho pouco efetivo com os orientandos.

Posturas equivocadas (por vezes opressoras) adotadas por orientadores podem ser fruto de falta de formação e não necessariamente de sentimentos negativos que nutrem pelos seus orientandos. A formação dos orientadores decorre, muitas vezes, de orientações que receberam ao longo de suas vidas acadêmicas e de buscas atreladas às suas curiosidades pessoais (WINCH; TERRAZZAN, 2011). Não que neguemos a possibilidade ou descartemos discrepâncias de personalidade como motores de relações desastrosas entre orientandos e orientadores, mas acreditamos que, mesmo com boas intenções, as idiossincrasias de estudantes e professores podem render convivências conflituosas sempre que não forem tratadas pela ótica pedagógica, que incluem conhecimentos relativos a ensinar como pesquisar, escrever, receber críticas, incorporar correções e, por que não dizer, conselhos de carreira e de vida.

RIAEE - Revista Ibero-Americana de Estudos em Educação, Araraquara, v. 16, n. esp. 1, p. 850-865, mar. 2021. e-ISSN: 1982-5587 


\section{Considerações finais}

O processo de orientação vem sendo abordado nas pesquisas de forma tímida, principalmente com relação ao contexto brasileiro. A maior parte das discussões atualmente se foca na orientação de disciplinas de estágio docente, essenciais na formação de profissionais de diversas áreas. Entretanto, ainda existe a necessidade de aproximar professores orientadores dos professores supervisores. As pesquisas focadas na orientação são, em sua maioria, estrangeiras, e nota-se uma ausência de discussões relacionadas ao planejamento didático deste processo.

A legislação educacional brasileira não explora o papel do orientador nos diferentes níveis de ensino, embora apresente a necessidade de supervisão e orientação no estágio docente de professores em formação. Nas diretrizes curriculares de cursos do Ensino Superior, a figura do orientador aparece como necessária para o desenvolvimento de monografias e outras atividades de formação profissional sem, contudo, explicitar quais são as atribuições de orientadores e orientandos. Professores são sobrecarregados e priorizam a orientação como uma atividade individual, visando a produção intelectual, o que, juntamente com a competição por fundos de pesquisa, tende a enfraquecer o potencial do processo de orientação.

Os casos, históricos e hipotéticos, se prestam para evidenciar posturas diversas de professores e estudantes ao longo do(s) processo(s) de orientação. Dos casos históricos, podemos depreender o papel do orientador em diversos contextos, influenciando os orientandos desde a construção da visão mundo, transmissão de capital intelectual e mesmo no apagamento de suas contribuições. Contudo, os registros históricos ainda carecem de um aprofundamento para o entendimento das relações orientador-orientando. Em contrapartida, os casos hipotéticos, inspirados em experiências reais, buscam detalhar aspectos de importância (psico)pedagógica do processo de orientação, por meio de diferentes posturas de orientadores e orientandos, em situações específicas, porém recorrentes.

A partir deste ensaio, esperamos contribuir para um maior esclarecimento sobre as bases que regem o(s) processo(s) da orientação, além de fomentar discussões, ampliando este campo temático. Práticas de capacitação centradas na questão da orientação são uma alternativa, dentre outras, que podem ampliar caráter educacional da orientação, geralmente construída com base em vivências, de forma pouco intencional e "desorientada". 


\section{REFERÊNCIAS}

ASSIS, R. L. M.; ROSADO, I. V. M. A unidade teoria-prática e o papel da supervisão de estágio nessa construção. Revista Katálysis, Florianópolis, v. 15, n. 2, p. 203-211, jul./dez. 2012. Disponível em: https://www.scielo.br/pdf/rk/v15n2/05.pdf. Acesso em: 30 ago. 2019.

BARRES, B. A. How to Pick a Graduate Advisor. Neuron, Cambridge, n. 80, p. 275-279, out. 2013. Disponível em:

https://www.sciencedirect.com/science/article/pii/S0896627313009070. Acesso em: 25 jun. 2020.

BLOOM, J. L. et al. Graduate Students' Perceptions of Outstanding Graduate Advisor Characteristics. NACADA Journal, Manhattan, v. 27, n. 2, p. 28-35, set. 2007. Disponível em: https://meridian.allenpress.com/nacada-journal/article/27/2/28/36210/Graduate-StudentsPerceptions-of-Outstanding. Acesso em: 28 abr. 2020.

BORDIGNON, R. R. Origens sociais, ascensão "profissional” e concepções de ciências sociais: Florestan Fernandes e Fernando Henrique Cardoso. Revista Tomo, Aracaju, n. 22, p. 181-220, jun. 2013. Disponível em: https://seer.ufs.br/index.php/tomo/article/view/1599. Acesso em: 30 jul. 2020.

BRASIL. Lei n. 9.394, de 20 de dezembro de 1996. Lei de Diretrizes e Bases da Educação Nacional. Diário Oficial da União: Seção 1, Brasília, DF, n. 248, p. 27833, 23 dez. 1996. PL $1258 / 1988$

BRASIL. Conselho Nacional de Educação (CNE). Conselho Pleno (CP). RESOLUÇÃo CNE/CP 1, DE 18 DE FEVEREIRO DE 2002. Institui Diretrizes Curriculares Nacionais para a Formação da Educação Básica, em nível superior, curso de licenciatura, de graduação plena. 2002a. Disponível em: http://portal.mec.gov.br/seesp/arquivos/pdf/res1_2.pdf. Acesso em: 20 set. 2018.

BRASIL. Conselho Nacional de Educação (CNE). Conselho Pleno (CP). RESOLUÇÃO CNE/CP 2, DE 19 DE FEVEREIRO DE 2002. Institui a duração e a carga horária dos cursos de licenciatura, de graduação plena, de formação de professores da Educação Básica em nível superior. 2002b. Disponível em:

http://portal.mec.gov.br/cne/arquivos/pdf/CP022002.pdf. Acesso em: 20 set. 2018.

BRASIL. Coordenação de Aperfeiçoamento de Pessoal de Nível Superior (CAPES). Portaria No 76, de 14 de abril de 2010. Regulamento do Programa de Demanda Social - DS. Diário Oficial da União: Seção 1, Brasília, DF, p. 31-32, 19 abr. 2010.

CARBELLO, S. R. C.; RIBEIRO, R. Anísio Teixeira e os desafios da primeira gestão na Inspetoria de Ensino da Bahia (1924-1929). Revista Ibero-Americana de Estudos em Educação, Araraquara, v. 10, n. 4, p. 1084-1094, out./dez. 2015. e-ISSN 1982-5587. Disponível em: https://periodicos.fclar.unesp.br/iberoamericana/article/view/8259. Acesso em: 20 abr. 2018.

CHEREP, M. Supervisors in the History of Science. Analysis of supervisor-student relations to discover who are the most important supervisors in history. Towards Data 
Science, 2020. Disponível em: https://towardsdatascience.com/supervisors-in-the-history-ofscience-deec27d19519. Acesso em: 28 abr. 2020.

CORRÊA, P. S. A. A orientação das dissertações e teses como objeto de estudo das pesquisas acadêmicas: história e historiografia. Revista HISTEDBR On-line, Campinas, n. 47, p. 392416, set. 2012. ISSN 1676-2587. Disponível em:

https://periodicos.sbu.unicamp.br/ojs/index.php/histedbr/article/view/8640059. Acesso em: 14 nov. 2017.

CURTIN, N.; STEWART, A. J.; OSTROVE, J. M. Fostering Academic Self-Concept: Advisor Support and Sense of Belonging Among International and Domestic Graduate Students. American Educational Research Journal, Nova Iorque, v. 50, n. 1, p. 108-137, fev. 2013. Disponível em: https://journals.sagepub.com/doi/10.3102/0002831212446662. Acesso em: 25 jun. 2018.

DANIEL, L. A. O professor regente, o professor orientador e os estágios supervisionados na formação inicial de futuros professores de Letras. Orientadora: Maria Inês Bacellar Monteiro. 2009. 140 f. Dissertação (Mestrado em Educação) - Universidade Metodista de Piracicaba, Piracicaba, 2009. Disponível em:

http://iepapp.unimep.br/biblioteca_digital/visualiza.php?cod=NTc5. Acesso em: 25 abr. 2020.

DIAS, S. M. R. C.; PATRUS, R.; MAGALHÃES, Y. T. Quem Ensina um Professor a ser orientador? Proposta de um Modelo de Orientação de Monografias, Dissertações e Teses. Administração: Ensino e Pesquisa, Rio de Janeiro, v. 12, n. 4, p. 697-721, out./dez. 2011. Disponível em: https://raep.emnuvens.com.br/raep/article/view/156. Acesso em: 26 nov. 2017.

FRAUCHES, C. C. Diretrizes curriculares para os cursos de graduação. Brasília: ABMES Editora, 2008.

FELDKERCHER, N. O trabalho dos professores orientadores de estágio em cursos de formação de professores. Revista Ibero-Americana de Estudos em Educação, Araraquara, v. 11, n. 4, p. 1799-1813, out./dez. 2016. e-ISSN 1982-5587. Disponível em: https://periodicos.fclar.unesp.br/iberoamericana/article/view/6032/6000. Acesso em: 22 nov. 2017.

KNOX, S. et al. A Qualitative Examination of Graduate Advising Relationships: The Advisor Perspective. The Counseling Psychologist, Nova Iorque, v. 34, n. 4, p. 489-518, jul. 2006. Disponível em: https://journals.sagepub.com/doi/10.1177/0011000006290249. Acesso em: 26 abr. 2020.

PETELENZ, B. Marie Skłodowska-Curie - on the shoulders of giants, thinking outside the box. Chemik, Varsóvia, v. 67, n. 8, p. 675-682, ago. 2013. Disponível em: https://journals.indexcopernicus.com/search/article?articleId=305087. Acesso em: 20 set. 2019.

PUNYANUNT-CARTER, N.; WRENCH, J. S. Advisor-Advisee Three: Graduate Students' Perceptions of Verbal Aggression, Credibility, and Conflict Styles in the Advising Relationship. Education, Mobile, v. 128, n. 4, p. 579-587, jun./ago. 2008. 
QUADROS, A. L.; DUARTE, F. C. T.; BOTELHO, M. L. S. T. Projetos universidade-escola: analisando a visão de ensino dos professores supervisores a partir da inserção nesses projetos. In: ENCONTRO NACIONAL DE PESQUISA EM EDUCAÇÃO EM CIÊNCIAS, 10., 2015, Águas de Lindóia. Anais [...]. Águas de Lindóia, SP: ABRAPEC, 2015. Disponível em: https://docplayer.com.br/124672933-Projetos-universidade-escola-analisando-a-visao-deensino-dos-professores-supervisores-a-partir-da-insercao-nesses-projetos.html. Acesso em: 25 nov. 2017.

SKWARZEC, B. Marie Sklodowska-Curie (1867-1934)-her life and discoveries. Analytical and Bioanalytical Chemistry, Berlim, n. 400, p. 1547-1554, mar. 2011. Disponível em: https://link.springer.com/article/10.1007/s00216-011-4771-3. Acesso em: 12 abr. 2019.

SOUZA, R. A.; MARTINELI, T. A. P. Considerações históricas sobre a influência de John Dewey no pensamento pedagógico brasileiro. Revista HISTEDBR On-line, Campinas, $\mathrm{n}$. 35, p. 160-172, set. 2009. ISSN 1676-2587. Disponível em:

https://periodicos.sbu.unicamp.br/ojs/index.php/histedbr/article/view/8639620. Acesso em: 12 abr. 2020 .

TRABATTONI, F. Platão. Coimbra: Imprensa da Universidade de Coimbra, 2012. 342 p.

UMPLEBY, S. Reflexivity in Social Systems: The theories of George Soros. Systems

Research and Behavioral Science, New Jersey, v. 24, n. 5, p. 521-522, nov. 2007.

Disponível em: https://onlinelibrary.wiley.com/doi/abs/10.1002/sres.852. Acesso em: 22 ago. 2019.

WINCH, P. G.; TERRAZZAN, E. A. Professores orientadores de Estágio Curricular: aspectos relativos à aprendizagem e à identificação com a atividade de orientação. Educação

Unisinos, São Leopoldo, v. 15, n. 1, p. 51-60, jan./abr. 2011. Disponível em:

http://revistas.unisinos.br/index.php/educacao/article/view/980. Acesso em 25 nov. 2017.

WIRTÉN, E. H. T. The Pasteurization of Marie Curie: A (meta)biographical experiment. Social Studies of Science, Thousand Oaks, v. 45, n. 4, p. 597-610, jun. 2015. Disponível em: https://journals.sagepub.com/doi/10.1177/0306312715589220. Acesso em: 30 set. 2019.

WOOLSTON, C. When labs go bad. Nature, Londres, v. 525, p. 413-415, set. 2015.

Disponível em: https://www.nature.com/articles/nj7569-413a. Acesso em: 28 jun. 2020. 


\section{Como referenciar este artigo}

GARCIA, P. M. P.; BONFIM, C. S.; GOMES, D M. A. O(s) processo(s) de orientação: reflexões a partir de casos históricos e hipotéticos. Revista Ibero-Americana de Estudos em Educação, Araraquara, v. 16, n. esp. 1, p. 850-865, mar. 2021. e-ISSN: 1982-5587. DOI: https://doi.org/10.21723/riaee.v16iEsp.1.14919

Submissão em: 20/06/2020

Revisões requeridas em: 16/09/2020

Aceito em: 03/11/2020

Publicado em: 01/03/2021 